\title{
Produção e parâmetros fisiológicos do amendoim em função do estresse salino
}

\author{
Production and physiological parameters the peanut \\ as a function of salt stress
}

\author{
Delfran Batista dos Santos ${ }^{1}$, Paulo Afonso Ferreira ${ }^{2}$, Flavio Gonçalves de Oliveira ${ }^{3}$, \\ Rafael Oliveira Batista ${ }^{4}$, Alan Carlos Costa ${ }^{5}$, Marco Antonio Oliva Cano 6
}

\begin{abstract}
RESUMO
O trabalho teve por objetivo avaliar os efeitos da salinidade da água de irrigação sobre o a condutividade elétrica do extrato da pasta saturada do solo (CEes) e as alterações dos parâmetros fisiológicos e de produtividade da cultura do amendoim. O experimento foi instalado no delineamento em blocos casualizados, com seis tratamentos e quatro repetições. Os tratamentos consistiram de seis frações de lixiviação, equivalentes a 40,30, 20, 10, 5 e 0\% da lâmina de água de irrigação, sendo que para a fração de lixiviação de $0 \%$ usou-se água doce $\left(0,1 \mathrm{dS} \mathrm{m}^{-1}\right)$ e para as demais água salina $\left(3 \mathrm{dS} \mathrm{m}^{-1}\right)$. Os resultados mostraram que aCEes diminuiu significativamente com o aumento das frações de lixiviação, o decréscimo do potencial osmótico foliar na planta de amendoim implicou na redução da produtividade e o teor de clorofila e a massa de matéria seca total reduziram significativamente com o aumento da CEes.

Palavras-chave: Arachis hypogaea, fração de lixiviação, potencial osmótico.
\end{abstract}

\begin{abstract}
The present study aims to evaluate the effect of water salinity from irrigation on the electrical conductivity of the saturated extract of soil (CEes) and the alterations of the physiological parameters and productivity on peanut cultivation. The experiment was conducted in a randomized block design with six treatments and four replications. The treatments consisted of a control with low

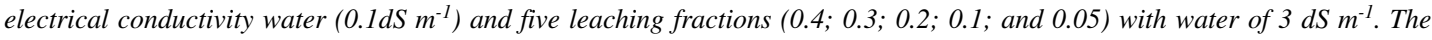
results showed that the CEes decreased significantly with the increase of the leaching fractions; the decrease of the leaf osmotic potential in the peanut plant implied the reduction of productivity; the content chlorophyll and the total dry matter decreased significantly with the increase of the CEes.
\end{abstract}

Key words: Arachis hypogaea, leaching fractions, osmotic potential.

\section{Introdução}

Historicamente a salinização de áreas de produção agrícola, tem resultado na substituição de culturas mais sensíveis por outras tolerantes, isto tem dado aos agricultores e principalmente aos irrigantes a possibilidade de, juntamente com outras técnicas de manejo, utilizar áreas com problemas de salinidade e mesmo assim obter produções sustentáveis econômica e ambientalmente (Leal et al., 2008; Santos et al, 2011).
A redução do crescimento e produtividade observada em muitas plantas submetidas à excessiva salinidade está frequentemente associada a diminuição na sua capacidade fotossintética (Neves et al., 2009). Os processos de crescimento das plantas são particularmente sensíveis ao efeito dos sais, de forma que a taxa de crescimento e a produção de biomassa são bons critérios para avaliação do grau de estresse e da capacidade da planta de superar o estresse salino (Morais et al., 2011).

1 Instituto Federal de Educação, Ciência e Tecnologia Baiano, Campus Senhor do Bonfim, Senhor do Bonfim, Bahia. 48970000. E-mail: delfran.batista@gmail.com

2 Universidade Federal de Viçosa, Departamento de Engenharia Agrícola, Viçosa, MG.

3 Universidade Federal de Minas Gerais, Instituto de Ciências Agrárias, Montes Claros, MG.

4 Universidade Federal Rural do Semiárido, Departamento de Ciências Ambientais e Tecnologicas, Mossoró, RN.

5 Instituto Federal de Educação, Ciência e Tecnologia Goiano, Campus Rio Verde, GO.

6 Universidade Federal de Viçosa, Departamento de Fisiologia Vegetal, Viçosa, MG. 
Segundo, Echer et al. (2010) um decréscimo na turgescência pode causar o decréscimo na taxa de crescimento, sendo que, pequenas diminuições no conteúdo de água e na turgescência podem reduzir a velocidade do crescimento ou até impedi-lo completamente.

Para determinar a tolerância da cultura à salinidade, um dos métodos utilizados é determinar a capacidade de ajustamento osmótico da planta (Silva et al., 2009; Araujo et al., 2006), definido como a diminuição do potencial osmótico em resposta ao déficit hídrico ou a salinidade, devido à acumulação de açúcares, aminoácidos e íons orgânicos no vacúolo.

O uso de água salina na agricultura é um procedimento de grande interesse devido ao aumento da demanda de água tanto pela atividade agrícola quanto pelo abastecimento urbano e industrial. Solos e água salinos são encontrados extensivamente sob condições naturais. Segundo, Rhoades et al. (1999), o modo prático e eficaz para reduzir o excesso de sais solúveis nos solos é a lixiviação através da passagem de água no perfil do solo, a uma taxa que permite manter a salinidade média na zona radicular a valores que não prejudicam economicamente a produtividade das culturas.

$\mathrm{O}$ amendoim (Arachis hypogaea L.) é uma oleaginosa de grande importância econômica, cultivada em boa parte do globo terrestre, para atender a indústria química e alimentícia; na região semiárida ela é apontada como alternativa de rentabilidade para os pequenos produtores (Freitas, 2011). Entretanto, para viabilizar a exploração dessa cultura em diferentes ecossistemas faz-se necessário conhecer o comportamento dos parâmetros fisiológicos quando submetidos a diferentes tipos de estresse (Erismann et al., 2006; Graciano et al., 2011).

Diante do exposto esse trabalho teve por objetivo avaliar os efeitos das frações de lixiviação com água salina sobre o extrato da pasta saturada do solo e as alterações dos parâmetros fisiológicos e de produtividade da cultura do amendoim (Arachis hypogaea L.) cv. BR-1.

\section{Materiais e Métodos}

O experimento foi conduzido em casa-de-vegetação no Laboratório de Unidade de Crescimento de Plantas (UCP) na Universidade Federal de Viçosa (UFV) - MG, a $649 \mathrm{~m}$ de altitude, $20^{\circ} 45^{\prime}$ latitude S e longitude $42^{\circ} 52^{\prime} \mathrm{W}$, no período de 10.12 .2003 a 21.03.2004.
Como material vegetal, utilizou-se o amendoim (Arachis hypogaea L.) cultivar BR-1, fornecido pela Embrapa Algodão. Os recipientes utilizados para o plantio foram vasos plásticos com capacidade de 3,5 L, que foram preenchidos até $2 \mathrm{~cm}$ da borda com 3,5 Kg de solo. O material de solo utilizado foi um Argissolo Vermelho Eutrófico, de textura argilosa.

Foram semeadas cinco sementes por vaso, e dez dias após a germinação foi feito o desbaste, deixando apenas as duas plantas mais vigorosas. Onde uma planta foi utilizada para determinação dos parâmetros fisiológicos e a outra para a determinação da massa de matéria seca, na ocasião da colheita.

A água utilizada nas irrigações foi preparada mediante adição de $\mathrm{NaCl}, \mathrm{CaCl}_{2}$ em quantidades para se obter uma condutividade elétrica (CEai) de $3 \mathrm{dS} \mathrm{m}^{-1}$. Com proporções iônicas equivalentes à $3: 2$, respectivamente para relação $\mathrm{Na}: \mathrm{Ca}$, que é predominante nas águas de alta salinidade utilizadas para irrigação no Nordeste (Medeiros et al., 2010).

O turno de rega utilizado nas irrigações foi de quatro dias, o volume de água aplicado foi estimado em função da evapotranspiração da cultura para o período. O experimento foi instalado no delineamento em blocos casualizados, com seis tratamentos e quatro repetições. Os tratamentos consistiram de seis frações de lixiviação, equivalentes a 40, 30, 20, 10,5 e $0 \%$ da lâmina de água de irrigação, sendo que para a fração de lixiviação de $0 \%$ usou-se água doce $\left(0,1 \mathrm{dS} \mathrm{m}^{-1}\right)$ e para as demais água salina $\left(3 \mathrm{dS} \mathrm{m}^{-1}\right)$.

Os dados diários de temperatura, umidade relativa do ar e radiação solar incidente foram registrados durante o ciclo da cultura. Em razão do experimento ter sido conduzido em ambiente protegido, as precipitações e a velocidade do vento não foram consideradas.

As avaliações do teor clorofila e potencial osmótico foram realizadas no período da floração e a determinação da massa de matéria seca foi realizada no final do ciclo no momento da colheita. O teor de clorofila (índice SPAD) foi medido com o medidor portátil SPAD-502 da Minolta. Para determinação do potencial osmótico, as folhas foram coletas, acondicionadas em sacos plásticos e armazenadas em freezer. Após o congelamento as folhas foram esmagadas com auxilio de uma prensa e o extrato foi centrifugado a $3.000 \mathrm{~g}$ durante 15 minutos a $4^{\circ} \mathrm{C}$. Uma alíquota de $10 \mu \mathrm{L}$ do sobrenadante foi utilizada para determinação da osmolalidade do 
tecido foliar do amendoim, usando um osmômetro da marca Osmette, modelo 2007.

As massas de matéria seca da parte aérea e da raiz foram determinadas após secagem do material em estufa de circulação de ar forçado, a temperatura de $65^{\circ} \mathrm{C}$, durante 72 horas até atingir peso constante.

Os dados foram submetidos à análise de variância e de regressão escolhidos baseando-se na significância dos coeficientes de regressão utilizando-se o teste " $t$ ", adotando o nível de até $10 \%$ no coeficiente de determinação, e no processo em estudo.

\section{Resultados e Discussão}

Em relação à condição climática durante o período experimental, o regime térmico apresentou oscilação com valores médios diários variando entre 20 a $28^{\circ} \mathrm{C}$, sendo que a média geral para o período em observação foi de $25^{\circ} \mathrm{C}$. A umidade relativa média oscilou entre 64 e $95 \%$, sendo que a média geral para o período foi de $79 \%$; a radiação solar média incidente também apresentou grande oscilação durante o ciclo da cultura, com valores oscilando entre 2 e $14 \mathrm{MJ} \mathrm{m}^{-2}$, sendo que a média geral para o período foi de $8 \mathrm{MJ} \mathrm{m}^{-2}$.

A condutividade elétrica do extrato da pasta saturada do solo (CEes) diminuiu linearmente com o aumento das frações de lixiviação (Figura 1). Esses resultados estão de acordo com estudos realizados por Silveira et al. (2008) e Carvalho et al. (2012), comprovando que a lixiviação, resultante da passagem de água através do perfil do solo, é uma prática eficaz utilizada para reduzir o excesso de sais solúveis na zona radicular das culturas.

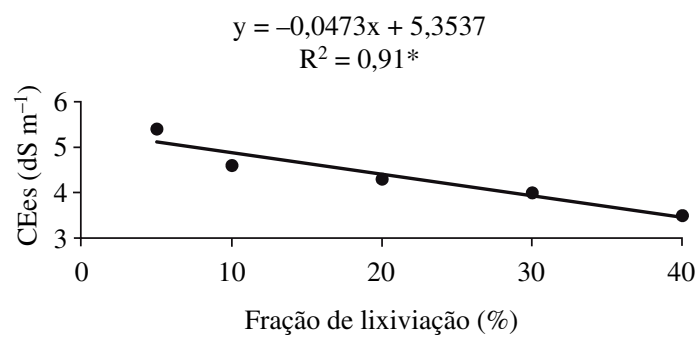

Figura 1. Variação da condutividade elétrica do extrato da pasta saturada do solo (CEes) em função das cinco frações de lixiviação com água de $3 \mathrm{dS} \mathrm{m} \mathrm{m}^{-1}$. Nível de significância $\mathrm{p}>0,05$.

Esses resultados estão de acordo com estudos realizados por alguns autores (Silveira et al., 2008; Carvalho et al., 2012), comprovando-se que a lixiviação, resultante da passagem de água através do perfil do solo, é uma pratica eficaz utilizada para reduzir o excesso de sais solúveis na zona radicular das culturas.

Em razão dos resultados obtidos na Figura 1, todas a discussão de agora em diante serão embasadas na condutividade elétrica do extrato da pasta saturada do solo, visto que, as plantas reagem à salinidade média do perfil do solo, expressa pela salinidade do extrato da pasta saturada (Medeiros et al, 2009).

O potencial osmótico das folhas ( $\Psi$ s) diminuiu linearmente com o aumento da condutividade elétrica média do extrato de saturação do solo (Figura 2). O modelo linear ajustado aos dados, apresenta uma redução de 1,04 MPa no valor do $\Psi$ s, por acréscimo unitário da condutividade elétrica da pasta saturada do solo, no intervalo em estudo.

Esse tipo de comportamento pode ser considerado uma estratégia adaptativa da espécie em relação ao aumento da concentração salina na solução do solo, possibilitando a hidratação dos tecidos vegetais e assim retardando os processos deletérios causados pelo déficit hídrico em função do aumento da concentração osmótica da solução do solo. Há evidência clara que a planta de amendoim, de alguma forma se ajusta osmoticamente para absorver água de uma solução com elevada concentração de sais.

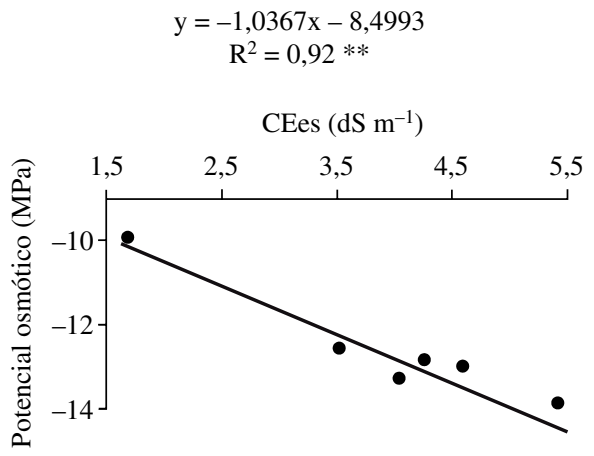

Figura 2. Potencial osmótico (MPa) da parte aérea de plantas de amendoim cultivadas em solos com diferente condutividade elétrica média do extrato da pasta saturada do solo $\left(\mathrm{dS} \mathrm{m}^{-1}\right)$. **Nível de significância $\mathrm{p}>0,01$.

O teor de clorofila reduziu linearmente com o aumento da condutividade elétrica média do extrato de saturação do solo (Figura 3). O modelo linear ajustado aos dados, apresenta redução de 2,25 índice SPAD no valor da clorofila nas folhas, por acréscimo unitário da condutividade elétrica 
da pasta saturada do solo, no intervalo em estudo. A redução do conteúdo de clorofila, em função do efeito da salinidade também foi observada em cana-de-açúcar (Willadino et al., 2011).

Elevadas concentrações de $\mathrm{NaCl}$ aumenta a degradação de clorofilas via atividade clorofilase, e diminuir a sua síntese, em virtude da competição por nitrogênio com outros compostos, como prolina (Ibarra \& Maiti, 1995). De acordo Santos, (2005) a degradação da clorofila, pode ocasionar uma considerável redução na taxa fotossintética e como consequência, redução na produtividade.

A massa de matéria seca total sofreu redução com o aumento da condutividade elétrica do extrato de saturação do solo (Figura 4). Tal evidência tem sido um comportamento clássico verificado em outros estudos quando as plantas são submetidas ao estresse salino (Blanco et al., 2008; Medeiros et al., 2011; Maciel et al., 2012). A redução no potencial hídrico da folha gerada pelo efeito osmótico da solução salina dificulta a absorção de água pelas raízes das plantas e, conseqüentemente, reduz a turgescência foliar. De acordo Ávila et al. (2007), com a redução da turgescência ocorrerá uma redução

(a)

$$
\begin{gathered}
y=-0,2515 x^{2}+1,7002 x-0,2983 \\
R^{2}=0,59^{\circ}
\end{gathered}
$$

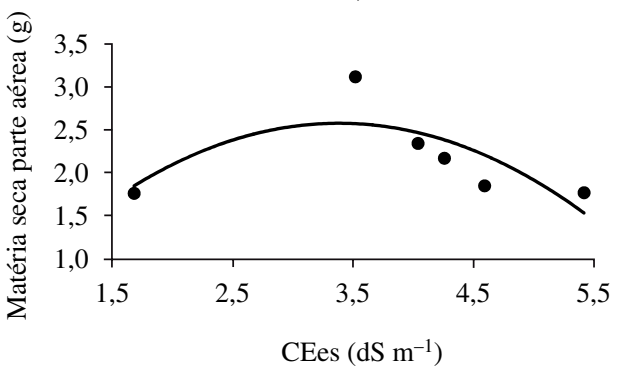

(c)

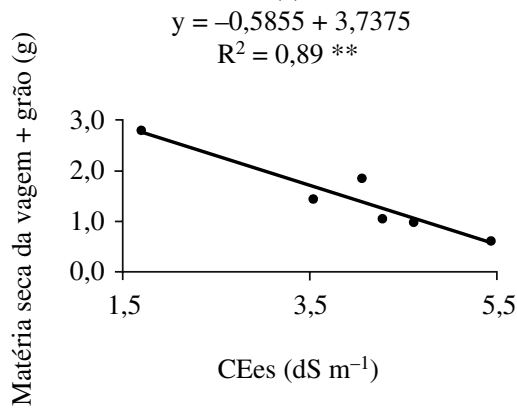

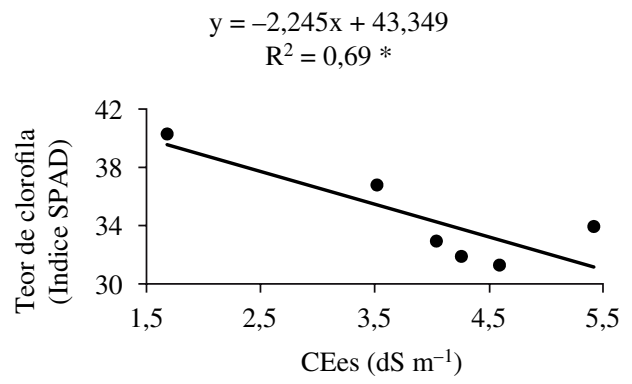

Figura 3. Teor de clorofila (índice SPAD) em folhas de plantas de amendoim cultivadas em solos com diferente condutividade elétrica média do extrato de saturação (CEes). *Nível de significância $\mathrm{p}>0,05$.

na taxa de crescimento. Possivelmente, tendo em vista a diminuição do tamanho das plantas e das folhas, a planta reduz a superfície de transpiração e a área exposta para captar radiação, e transpirando menos, irá absorver menos nutrientes via solução do solo e realizar menos troca de $\mathrm{CO}_{2}$ com o meio ambiente, o que irá reduzir seu potencial fotossintético e consequentemente sua produtividade.

Em trabalho conduzido com a cultura do amendoim cultivar BR-1, em casa de vegetação no

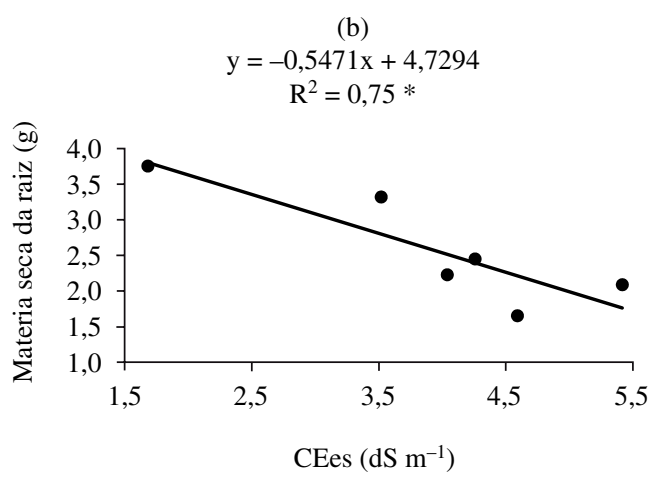

(d)

$y=-2085 x^{2}+0,2722 x+8,6016$

$\mathrm{R}^{2}=0,84 * *$

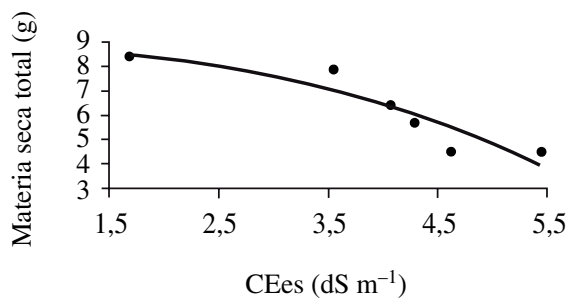

Figura 4. Massa de matéria seca do caule e folha (a), da raiz (b), das vagens e grãos (c) e massa de matéria seca total (d) de amendoim, cultivado sob diferentes condutividades elétricas médias do extrato da pasta saturada do solo (CEes). **,* $\mathrm{e}^{\circ}$ significativos do nível de 1,5 e $10 \%$ de probabilidade, respectivamente. 

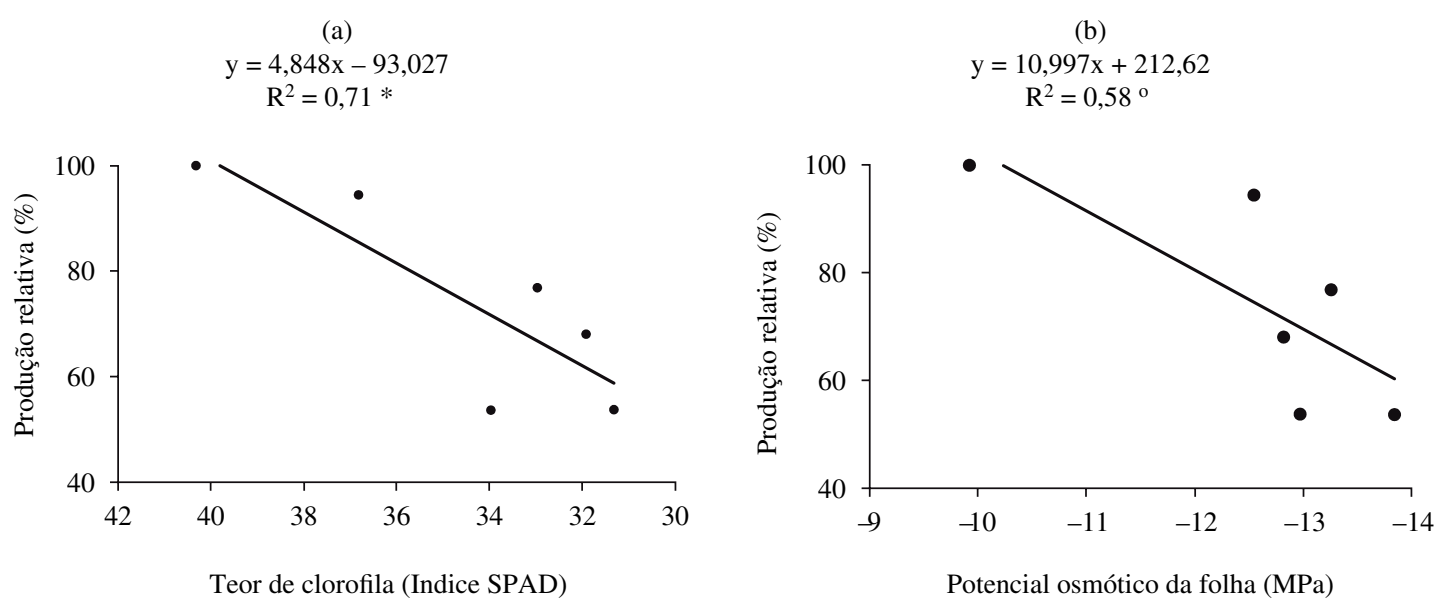

Figura 5. Relação entre a produção relativa (\%) o teor de clorofila (índice SPAD) (a) e o potencial osmótico (MPa) (b).

Semiárido Nordestino também foi observado que a salinidade da água de irrigação afetou negativamente todas as variáveis de crescimento e produção estudadas (Correia et al., 2009).

A produção relativa diminui linearmente em função do decréscimo do teor de clorofila, apresentando uma redução de $4,8 \%$ na produtividade por decréscimo unitário do teor de clorofila das folhas, no intervalo em estudo (Figura 5a). A produção relativa também diminui linearmente em função do decréscimo do $\Psi_{\mathrm{s}}$, apresentando uma redução de $11 \%$ na produtividade por decréscimo unitário do $\Psi_{\mathrm{s}}$, no intervalo em estudo. Essa tendência pode ser atribuída ao fato da planta com intuito de ajustar-se osmoticamente se desprenderá uma determinada quantidade de energia para acumulação de açúcares, ácidos orgânicos e íons no vacúolo, energia essa, que poderia ser utilizada no crescimento e desenvolvimento da planta.

\section{Conclusões}

A condutividade elétrica do extrato da pasta saturada do solo diminui significativamente com o aumento das frações de lixiviação;

$\mathrm{O}$ teor de clorofila (índice SPAD) reduz significativamente com o aumento da condutividade elétrica média do extrato de saturação do solo;

Há evidência clara que a planta de amendoim, de alguma forma se ajusta osmoticamente para absorver água de uma solução com elevada concentração de sais;

A massa de matéria seca total diminui significativamente com o aumento da condutividade elétrica média do extrato de saturação do solo;

Um decréscimo no potencial osmótico foliar na planta de amendoim implica na redução da produtividade.

\section{Literatura Citada}

Araújo, S.A.M.; Silveira, J.A.G.; Almeida, T.D.; Rocha, I.M.A.; Morais, D.L.; Viégas, R.A.

2006 Tolerância à salinidade da halófita Atriplex nummularia L. cultivada em níveis crescentes de $\mathrm{NaCl}$. Revista Brasileira de Engenharia Agrícola e Ambiental. 10(4): 848-854.

Ávila, M.R.; Braccini, A. de L.; Scapim, C.A.; Fagliari, J.R.; Santos, J.L. dos.

2007 Influência do estresse hídrico simulado com manitol na germinação de sementes e crescimento de plântulas de canola. Revista Brasileira de Sementes. 29(1): 98-106.

Azevedo Neto,A.D. de; Pereira, P.P.A.; Costa, D.P.; Santos, A.C.C. dos. 2011 Fluorescência da clorofila como uma ferramenta possível para seleção de tolerância à salinidade em girassol. Revista Ciência Agronômica. 42(4): 893-897.
Blanco, F.F.; Folegatti, M.V.; Gheyi, H.R.; Fernandes, P.D. 2008 Crescimento e produção do milho irrigado com água salina. Scientia Agrícola. 65(6): 574-580.

Carvalho, J.F. de; Tsimpho, C.J.; Silva, E.F. de F.E.; Medeiros, P.R.F. de; Santos, M.H.V.; Santos, A.N. dos.

2012 Produção e biometria do milho verde irrigado com água salina sob frações de lixiviação. Revista Brasileira de Engenharia Agrícola e Ambiental. 16(4): 368-374.

Correia, K.G.; Fernandes, P.D.; Ghey, H.R.; Nobre, R.G.; Santos, T. da S.

2009 Crescimento, produção e características de fluorescência da clorofila em amendoim sob condições de salinidade. Revista Ciência Agronômica. 40(4): 514-521. 
Echer, F.R.; Custódio, C.C.; Hossomi, S.T.; Dominato, J.C.; Machado Neto, N.B.

2010 Estresse hídrico induzido por manitol em cultivares de algodão. Revista Ciência Agronômica. 41(4): 638-645.

Erismann, N. de M.; Machado, Godoy, E.C.; I.J. de. 2006 Capacidade fotossintética de genótipos de amendoim em ambiente natural e controlado. Pesquisa Agropecuária Brasileira. 41(7): 1099-1108.

Freitas, G.A. de.

2011 Produção e área colhida de amendoim no nordeste. $3^{\mathrm{a}}$ ed. Banco do Nordeste, Fortaleza, 8 pp.

Graciano, E.S.A.; Nogueira, R.J.M.C.; Lima, D.R.M.; Pacheco,

C.M.; Santos, R.C.

2011 Crescimento e capacidade fotossintética da cultivar de amendoim BR 1 sob condições de salinidade. Revista Brasileira de Engenharia Agrícola e Ambiental. 15(8): 794-800.

Ibarra, M. \& Maiti, R.K.

1995 Biochemical mechanism in Glossy Sorghum lines for resistance to salinity stress. Journal Plant Physiology, 146: 515-519.

Leal, I.G.; Accioly, A.M. de A.; Nascimento, C.W.A. do; Freire,

M.B.G. dos S.; Montenegro, A.A. de A.; Ferreira, F. de L.

2008 Fitorremediação de solo salino sódico por Atriplex nummularia e gesso de jazida. Revista Brasileira de Ciência do Solo. 32(3): 1065-1072.

Maciel, M.P.; Soares, T.M. Gheyi, H.R; Rezende, E.P.L.;

Oliveira, G.X.S.

2012 Produção de girassol ornamental com uso de águas salobras em sistema hidropônico NFT. Revista Brasileira de Engenharia Agrícola e Ambiental. 16(2): 165-172.

Medeiros, D.C. de; Medeiros, J.F. de; Dias, P.M.S; Barbosa,

M.A.G.; Lima, K. da S.

2011 Produção de melão Pele de Sapo híbrido 'Medellín' cultivado com diferentes salinidades da água. Revista Ciência Agronômica. 42(3): 628-634.

Medeiros, J.F.; Gheyi, H.R.; Dias, N.S.; Carmo, G.A.

2009 Riscos e medidas mitigadoras para a salinidade em áreas irrigadas. In: Paz, V. P. S., Oliveira, A. S., Pereira, F. A. C. \&Gheyi, H. R. (Org.). Manejo e sustentabilidade da irrigação em regiões áridas e semi-áridas. Cruz das Almas: UFRB, 1: 187-219.
Medeiros, J.F.; Nascimento, I.B.; Gheyi, H.R.

2010 Manejo do solo-água-planta em áreas afetadas por sais. In: Gheyi, H. R., Dias, N. S. \& Claudivan, F. L. (Org.). Manejo da salinidade na agricultura: Estudo básico e aplicado. 1 ed. Fortaleza, CE: INCT Sal, 1: 279-302.

Morais, F.A. de; Gurgel, M.T.; Oliveira, F.H.T. de; Mota, A.F. 2011 Influência da irrigação com água salina na cultura do girassol. Revista Ciência Agronômica. 42(2): 327-336.

Neves, A.L.R.; Lacerda, C.F. de; Guimarães, F.V.A.; Gomes

Filho, E.; Feitosa, D.R.C.

2009 Trocas gasosas e teores de minerais no feijão-de-corda irrigado com água salina em diferentes estádios. Revista Brasileira de Engenharia Agrícola e Ambiental. 13: 873-881.

Rhoades, J.D.; Chanduvi, F.; Lesch, S.

1999 Soil Salinity Assessment: Methods and interpretation of electrical conductivity measurements. Rome: FAO, $150 \mathrm{pp}$. (Irrigation and drainage Paper $N^{\circ} 57$ ).

Santos, D.B. dos.

2005 Efeitos da salinidade sobre características químicas do solo, aspectos nutricionais, fisiológicos e de produção no feijoeiro irrigado. Viçosa: UFV, 2005.78 pp. Tese Doutorado.

Santos, K.C.F. dos; Silva, M.S.L. da; Silva, L.E. da; Miranda, M.A.; Freire, M.B.G. dos S.

2011 Atividade biológica em solo salino sódico saturado por água sob cultivo de Atriplex nummularia. Revista Ciência Agronômica. 42(3): 619-627.

Silva, E.N. da; Silveira, J.A.G.; Rodrigues, C.R.F.; Lima, C.S. de; Viégas, R.A.

2009 Contribuição de solutos orgânicos e inorgânicos no ajustamento osmótico de pinhão-manso submetido à salinidade. Pesquisa Agropecuária Brasileira, 44(5): 437-445.

Silveira, K.R. da, Ribeiro, M.R.; Oliveira, L.B. de, Heck, R.J.;

Silveira, R.R. da.

2008 Água saturada com gesso na recuperação de solos aluviais salino-sódicos e sódicos. Scientia Agrícola. 65(1): 69-76.

Willadino, L.; Oliveira Filho, R.A. de; Silva Junior, E.A. da; Gouveia Neto, A.; Camara, T.R.

2011 Estresse salino em duas variedades de cana-de-açúcar: enzimas do sistema antioxidativo e fluorescência da clorofila. Revista Ciência Agronômica. 42(2): 417-422. 